that we may have to return to a certain Mosaic rite in order to save our wives from aterine cancer, unless the daily use of soap will do away with this necessity. I for one tender my greatest appreciation and thanks to Dr. Braithwaite for his very suggestive paper. It will be seen that in the first and third of these cases recurrence had taken place after a previous operation where removal of the os through the neck had been performed, and that the second was a primary case.

CASE 1.-A married woman aged fifty, mother of two children, had had good confinements ; eight months previously she was first tronbled with a white discharge from the vagina. In September, 1894, she was admitted into the Chelsea Hospital for Women under the care of Dr. Dancan, who operated and amputated the os. She was admitted into the Cancer Hospital on Dec. 3rd, 1894, and stated that since the previou; operation she had had a continual bloody discharge. On examination the vagina was found to be long, and recurrence of malignant disease of the stump extending up the uterine canal was felt. The mucous membrane of the vagina posteriorly was dizeased. The patient was of a more or less happy disposition, and was fairly well nourished. On the $8 . h$ I performed vaginal hysterectomy. The mucous membrane was incised well clear of the disease. Some of the lisatures came away on the tenth day after operation, and the last ligature on the twenty-second day ; she made a good recovery and was discharged. I saw her six months afterwards and found a slight recurrence in the extreme vault. This I treated with iodine, what I call an iodine bath-that is, fixing the speculum firmly applied against the vault and then pouring sufficient liniment iodi down the speculum to cover the disease, which takes about half an ounce, and this is kept in contact for about five minutes and then ran off and the parts dried. Tais has been frequently repeated at intervals of a week, and it has certainly done good. This case is an example of recarrence from previous implication of the mucous membrane.

CASE 2 -A married woman aged forty-five years was the mother of nine children, the last one born seven years ago her lab jurs had been natural. The patient was recommended by Dr. Fitzgerald of Harrow-road, and was admitted to the Cancer Hospital on May 6ih, 1895. She had been troubled with a discharge for the previous two months, and had suffered from bearing-down pain and a dragging in the legs. She was always tired and every thing seemed a trouble. She was pale and of a placid disposition. On examination the vagina was found to be occupied by a large mass of epitheliomatous disease; the finger was with difficulty got round and the vaginal mucous membrane was felt to be smo $0^{+h}$ and apparently not infiltrated; high up in the neck anteriorly a boss was felt pressing forward; the uterus was fairly movable. Vaginal hysterectomy was performed on May 11th. The disease was very extensive, and was first removed by working with scissors from before backwards thruugh the neck; there was no bleeding. The parts were then freely donched out with carbolic solntion and the further steps for total removal followed; the ovaries were allowed to remain. The specimen when opened showed extensive disease and had near the fundus a cancerous nodule. The patient made a good recovery.

CASE 3 - The patient had been a widow for twelve years and wds mother of six children. She was admitted to the Cancer Hospital on April 25th, 1895, and complained of a puralen't discharge, which was sometimes bloody. On examination the vagina was found to be occupied by a fungating canliflower mass; the vaginal walls were not implicated, the fornices were high up, the uterus was movable, and the broad ligaments were free. Eight years previonsly she had been admitted into Middlesex Hospital, where the neck was amputated for disease of the os. On May 11th I performed vaginal hysterectomy. The diseased mass was first removed, and some difficulty was experienced in incising the mucous membrane. The operation of total removal was completed; the ovaries were left. Con ralescence was somewhat protracted, but the patient made a good recovery and was discharged.

These tbree specimens $I$ had the pleasure of exhibiting at the Bitish Gynæcological Society's meeting on the 11th inst. Manchester-square, W.

The Gaskell medal and prize in mental and nervous ciseases at the Koyal Bethlem Hospital bas bees a sarded after examination to Me. Georse W. F. Ma nau ghton, M.B., C.M. Edin.

\section{A FEW WORDS ON SOME COMMON FORMS OF REFLEXES OF NASAL ORIGIN. ${ }^{1}$}

BY ADOLPH BRONNER M.D.HEIDL.,

SURGEON TO THE BRADFORD EYE AND EAR HOSPITAL, AND LARYNGOLOGIST TO THE BRADFORD INIIRMARY.

A GREAT deal has been written on nasal reflexes. As far back as 1565 we find that Botallus records cases in which the scent of flowers brought on pain in the head and diffculty in breathing. Van Helmont in 1577 describes some typical cases of hay fever. Bostock ${ }^{2}$ was himself subject to hay fever. No great importance was, however, attached to this subject until 1871, when Voltolini ${ }^{3}$ published several cases of asthma in which nasal polypi were found, and where the removal of the polypi cured the asthma. Fraenkel, Lennoz Browne, and others soon followed suit, and proved that the cases recorded by Voltolini were by no means un. common. In 1881 Hack of Freiburg published his wellknown book on Nasal Reflexes, ${ }^{4}$ in which he attempts to prove that not only asthma, but many other similar symptoms can be caused by intra-nasal irritation. He divides these reflex symptoms into four classes-(1) spastic, (2) sensory, (3) vaso motor, and (4) secretory. Numerous cases are recorded of asthma, hay fever, megrim, supra. orbital neuralgia, swelling and redness of the nose, vertigo, epileptiform attacks, \&c., which had been cured by intranasal treatment. Hack's theory was that these reflex sym. ptoms were due to irritation of the terminal fibres of the fifth nerve, which irritation was caused by the swelling of the cavernous tissue of the mucous membrane of the turbinated bones, especially the anterior part of the lower turbinated bones. His idea was to remove this cavernous tissue by the galvano-cautery, and then any irritation of the nerves would be impossible. Experience, however, soon proved that this theory could not be quite correct. Then, in the first place, the destruction of the cavernous tissue did not always prevent a recurrence of the reflex symptoms. Secondly, in many cases artificial irritation of this part of the mucous membrane bronght on the reflexes without causing any swelling of the cavernous tissue. Hack himself, in $18855^{\circ}$ practically abandons his theory. In 1882 Fraenkel, J. Mackenzie, and others opposed Hack's theory, and stated that the reflexes were caused by some irritation of the terminal fibres of the fifth nerve, due to changes in the mucons membrane of the turbinated bones or septum, but that the swelling of the carernous tissue need not have anything whatever to do with the irritation. Lublinski, ${ }^{6}$ Heymann, and others think that the reflexes cannot occur unless there is a predisposing neurotic temperament. Boecker repudiates the reflex theory altogether, and states that the intra-nasal changes are mostly incidental complications or that they themselves form part of the symptoms of a central neurosis. In speaking of hay fever Morell Mackenzie ${ }^{7}$ said : "The causes of hay fever may be conveniently divided into the predisposing and the exciting. Race, temperament, occupation, education, mode of life, sex, heredity, and age are some of the predisposing causes." Mackenzie did not seem to believe in local treatment for the cure of hay fever. Everyday experience, however, proves that many cases of hay fever, though of course by no means all, are due to a reflex action originating in the nose. Woakes ${ }^{8}$ says that the reflexes are-(1) symptoms due to excitation of the sensory-motor nerve elements of the region implicated; and (2) those which involve vaso-motor nerves of the sympathetic system in relationship with the affected structures. As regards asthma, he thinks that it is due to irritation of or pressure on the nerve of Cotannius, where it crosses the osseous part of the nasal septum. I myself am of opinion that we ought to divide nasal reflexes into two classes : (1) those cases in which there is some local irritation of the terminal fibres of the fifth nerve, due to nasal polppus, pressure of the mucous membrane of the turbinated bones on

1 Abstract of a paper read before the Bradford Medico-Chirurgical Society, April, 1895

2 Transactions of the Royal Medical and Chirurgical Society, rol $\mathrm{x} ., 1819$. 3 Anwendung der Galvanokaustik, \&c. 4 Ueber eine Operative Radical Behandlung gewisser Formen ron Jigraine, Asthma, \&o. Berliner Klinische Wochenschrift, Nos. 21 and 22.
6 Deutsche Merlicinische Zeitschrift, No. 41, 1886 .

7 Hay Fever: its Etiology and Treatment, with an Appendix on Rose Cold. 1885 . 
the septrm, local atropby or hypertrophy of the mucous membrane of the turbinated bones or of the septum, disease of the turbinated bones themselves, foreign body in the nose, \&c. ; and (2) those cases in which the nasal changes are not primary, but are themselves the outcome of some central neurosis. In the latter class of cases the local treatment of the nares, such as the use of the galvano-cautery, stops the reflex symptoms, not because it removes the irritation, but because it acts as a powerful counter-irritant. McBride ${ }^{9}$ advocates this latter theory.

There can be no doubt that intra-nasal irritation can and trequently does give rise to reflex symptoms, such as asthma, hay fever, megrim, vertigo, and epileptiform attacks, bat it does not by any means follow that it is always the canse of these symptoms. We know that in many cases gastric or uterine irritation can give rise to similar symptoms. It follows, however, that it is absolutely necessary that in all these and similar cases the nares and postnasal space should be caref ully and thoronghly examined. If we can find any obstruction to the free passage of air, such as hypertrophy of the mucous membrane, polypi, deviation of the septum, post-nasal growths, \&c., or any changes in the mucous membrane (hypertrophy or polypoid degeneration, \&c ), these must be treated and cured. Even if the treatment does not remove the symptoms it cannot do the patients any harm, but must be of benefit in other respects. I need not refer to the connexion between these diseases and those of the ear and throat, and how any nasal obstruction prevents the normal development of the lungs and arrests the growth of the body and of the mind. Innumerable cases of asthma, hay fever, megrim, and supra-orbital neuralgia have been cured by intra-nasal treatment, and a large number have been recorded. I can call to mind a series of typical cases of asthma, hay fever, sneezing, megrim, and redness and swelling of the nose, which have come under my notice, and which have been cured in most cases by removal of nasal polypi or by the application of the galvano-cautery to the diseased mucous membrane of the lower turbinated bones. Bradford.

\section{A CASE OF POST-PARTUM TUBO-OVARIAN ABSCESS IN A PECULIAR POSITION.}

BY FREDERICK EDGE, M.D.LOND., F.R.C.S. ENG.

THE patient was a woman twenty-one years of age, of slight but active frame, and generally sound. Four montbs previously she was confined of her firstborn child, and she informed me that she had had a severe confinement There was no special cause of obstruction or hæmorrhage, neither was laceration to any degree of the parturient canal noticed. After the birth of the child the patient did not gain strength and recover quickly, bat had a severe illness with fever, pain in the left side of the pelvi and down the left leg, and a mass in the left side. When admitted there was no fever, but the pulse was from 90 to 100. She complained of pain in the left side and general debility. The pain was much increased if she was up for a short time. On examination of the abdomen a prominence in the iliac fossa was seen; this could be felt as a firm rounded, crescentic mass, in which fluctuation was doubtful, and it was dull on percussion. Per vaginam the uterus was felt to be fixed to a mass on the left side which spread to the pelvic wall. Bimanually the uterus could be felt distinctly, and a boundary marking it from the lateral mass, but not separating it by any division, was perceived by a difference in consistence and ronghness of outline. By the sound the aterine cavity was found slightly enlarged and dilated, but not more than one would find often at the same period after labour. The mass did not push down the posterior fornix and the posterior wall of the uterus was free. As there were no urgent symptoms the patient was kept at perfect rest for six weeks, and her bowels were constantly emptied by saline aperients; alteratives and absorptives, counterirritants, with ichthyol-gly cerine applications in the vagina and hot donches and enemata, were all carefully tested, and their conjoint action was accompanied by a gradual lessening of the swelling, and would, perhaps, have attended its disappearance if the patient could have been rested indefinitely. At the end of six weeks she was allowed up for a couple of

9 Brit. Med. Jour., Jan. 22nd, 1887. hours, and she next morning noticed a great increase in the size of the mass and in the pain and discomfort. From the shape of the swelling, its position, the absence of fever, and its history, I diagnosed the condition as one of pyosalpinx with cellulitis of the broad ligament, and as I could not keep the patient on ber back indefinitely, she being a labouring woman, I thought it would be good practice to explore, as d, if found, to remove the pyosalpinx. On opening the abdomen great adhesions were separated, and then for some time I could not make out the condition of the parts, or what I had to deal with, or what I was going to do. The pouch of Douglas was free, which ratber put me off pyosalpinx, and I was inclined to think that I had to deal with a simple plastic cellulitis of the left broad ligament. The omentum was in a column or rolled bundle, and was adberent widely in the left iliac fossa, which is uncommon in simple cellnlitis. I tried to separate its adhesions, but failed, as the bleeding became severe. I then tied the whole omental bundle in two places, cutting between. It was evident now that the tube and ovary were implicated, and the resulting mass, which contained a fluctuating cyst of Tangerine orange size, was fixed high on the left pelvic wall and in the left iliac fossa, where the omentum bad covered it and adhered to it and the parietal peritoneum. The tube and ovary and broad ligament with omentum were removed, together with some parietal peritoneum which was torn off. The attarhments were tied off in two pedicles, one at the horn of the uterus and the other at the pelvic wall. The separation was very difficult, and the sigmoid flezure, which was intimately adherent, was badly torn, but not sufficiently in any place, so far as was noticed, to require suturing. A Keith glass drainage-tube was nsed after washing out with Mr. Lawson Tait's apparatus. The patient's pulse and temperature before ocera'tion were 90 and $98^{\circ} \mathrm{F}$. respectively. There were collapse ard great pain, so that an injection of morphia was given (in my own abdominal sections I have only given morphia twice before, and each patient died, so that necessity is great before I use mork hia). An enema of one teaspoonful of common salt, half an ounce of branc' $y$, one ounce of milk, and five ounces of water was given three times in the night. On the evening of operation the pulse was 124 and the temperature $98^{\circ}$. The next day the pulse was 140 and the temperature $98.8^{\circ}$. Slight distension. was treated by calomel and enemata of soap, turpentine, glycerine, and castor oil. At 9 P.M. the pulse was 152 and the temperature $99.2^{\circ}$. The bowels did not act either with flatus or fæces, and two days afterwards fæcal matter exuded from the abdominal wourd freely. As the enemata were irritant they were changed into free irrigation of the rectum with normal saline soluticn, whicb, passing upwards, helped to clear the abdominal channel The patient gradually improved, and although the fæces passed through the abdominal incisicn alone for three days she felt better. Gradually more passed per anum, and now the fistula is almost closed. She is walking about at present and gaining strength and flesh.

These fistu' $x$ are very chronic, and no doubt the silk ligatures act as setons. The points of interest in this case are to my mind as follows. 1. The absence of fever when the patient was kept resting. This seems to point away from pus in any cellular tissue and is more in accord with pus contained in a cavity lined by mucous membrane or its homologue as an ovarian follicle. 2. The peculiar posi ion of the mass of exudation and adbesicns arcund the cyst containing pus. In these cases of post-partum suppuration of the append?ges it must be remembered that the germs have already gained access to these parts often at or before conception from the other side has taken place. They are generally unilateral ; hence the tube which is carrica up into the level of the iliac fossa durirg pregnarcy, if inflamed, would form adhesions at this level, and after labour the descent of the uterus would tend to drag upon the adbesion and permit leakage, which wonld excite peritonitis and fix the omentum. A condition similar to this, if not the same, was described by Mr. J. W. Taylor, and he pointed out in certain cases the difficulty of making out such a tabe sac owing to its position. 3. The frequence of pcst-partum suppuration in the tubes and ovaries. When we reflect on the possibilities which the corpus luteum of the ovary. a mass of lowly organised clot, offers, the widely patent tabe in which ciliated epithelium must be merely side fringes at these times, and the uterine and vaginal states, we canr ot be surprised at this. The abscess usually distends the ovary, but the tube mouth is spread on the ovary, and if detached the 